\title{
Importance of the Running-In Phase on the Life of Repairable Systems
}

\author{
Salima Beleulmi ${ }^{1}$, Ahmed Bellaouar ${ }^{2}$, Mohammed Lachi ${ }^{3}$ \\ ${ }^{1}$ Department of Mechanical Engineering, Laboratory of Environment and Transportation Engineering, \\ Faculty of Technology, University of Constantine 1, Constantine, Algeria \\ ${ }^{2}$ Laboratory of Environment and Transportation Engineering, University of Constantine 1, Constantine, Algeria \\ ${ }^{3}$ Laboratory of Thermo Mechanical, University of Reims Champagne-Ardenne, Champagne-Ardenne, France \\ Email: salima_b05@yahoo.fr, bellaouar_ahmed@yahoo.fr
}

Received December 10, 2013; revised January 10, 2014; accepted January 17, 2014

Copyright (C) 2014 Salima Beleulmi et al. This is an open access article distributed under the Creative Commons Attribution License, which permits unrestricted use, distribution, and reproduction in any medium, provided the original work is properly cited. In accordance of the Creative Commons Attribution License all Copyrights (C) 2014 are reserved for SCIRP and the owner of the intellectual property Salima Beleulmi et al. All Copyright (c) 2014 are guarded by law and by SCIRP as a guardian.

\section{ABSTRACT}

The running-in phase is the first stage of the bearing lifespan. However, this phase is very short and extremely important for the future lifespan of the rolling bearing because it is what sets the stabilized state in terms of roughness of the parts in contact, residual geometry and surface residual stresses, which are key factors in the fatigue resistance of mechanical parts. Several numerical and experimental studies have highlighted the importance of the running-in phase in two scales (macroscopic, meso and microscopic). Due to its high flexibility, the approach presented in this work is a numerical modeling of the running-in phase which has been based on the Weibull distribution. The obtained results confirm the importance of the running-in phase on the lifespan of bearings or other mechanism whose functioning requires an adaptation phase of parts in contact. It also concludes that if the running-in phase has been performed correctly, there is a marked improvement in reliability. The curves describe the useful saved time of lifespan according to the scale of the running-in phase.

\section{KEYWORDS}

\section{Running-In Phase; The Useful Lifespan; Bearings; Numerical Modeling}

\section{Introduction}

The reliable assessments of mechanical systems are based on many parameters where the failure rates are the first considered. By default, databases are commonly used for reliability. For the most part are collections of data [1-3] and many others from the feedback experience of various sectors. Potential users of these are based on the fact that their materials are substantially similar and that the reliability of these databases can be transferred to their concerns. One can observe that the data of studied systems reliability are not homogeneous, as is sometimes suggested significant variations of the failure rates between bases. The causes are many: Materials have their own characteristics. Same type of system comes in a range of equipments whose reliability is different; operating conditions and operating environment vary between systems. Reliability of mechanical equipment is sensitive to loading, operating modes, stresses, failure modes considered, maintenance politicizes... These differences are highlighted between the sectors; to synthesize the data collected for each type of system often requires regrouping irrespective equipments to various intrinsic and extrinsic properties, regardless of characteristics. The use of these databases as input data of reliability assessments will therefore result in large uncertainties about the relevance of the results. The second point to be noted is that all the databases described above only provide constant failure rates. However, the mechanisms of degradation of mechanical components such as fatigue, vibration, la corrosion and other stresses creating wear phenomena, therefore the system ages. To this a running-in phase that usually causes failures in young systems can be added. In what follows, the running-in phase is to be modeled in order to highlight its importance in the total lifetime of the mechanism. The example cited in this study is the 
case of bearings that are virtually present in the majority of mechanical systems. Although their lifetime is relatively short compared to the entire mechanism in which are mounted, but their running-in phase provides a significant mechanical stability [4].

\section{Failure Rate Base $\lambda(0)$}

It has been seen earlier that the mechanical equipments rarely respond to a constant failure rate, synonymous with exponential probability distribution. Here, a model by the Weibull distribution with two parameters has been proposed. The failure rate is expressed as follows:

$$
\lambda_{0}(t)=\frac{\beta}{\theta}\left(\frac{t}{\theta}\right)^{\beta-1}
$$

With:

$\beta$ the shape parameter, unit less;

$\theta$ the scale parameter in units of time. Sometimes, expression (1) is found in a form that puts the parameter $\lambda=\frac{1}{\theta}$.

This distribution is widespread in the reliability of mechanical systems as it allows to model three periods of system lifetime according to the parameter $\beta$. Figures 1(a)-(c), show respectively the different periods of lifetime, the corresponding behavior laws and the shape of the failure rates for mechanical systems.

A running period Figure 1(c), also known as infant mortality, if $\beta<1$. The failure rate is decreasing with time. Faults that appear in this first phase of life are typically due to faulty design or installation once the system started. Most of these failures can be avoided by test policies, before the introduction of equipment [5]. The running-in period may contribute substantially to the increase of the equipment lifetime. Some authors refer to the increase in wear after the running-in period [6-9].

A phase called useful life, if $\beta \approx 1$. The failure rate is then almost constant. Defects in removed equipment, the system is in its main phase of life. Failures that occur during this period are caused by random events independent of time and age of system.

A phase of wear, if $\beta>1$. The failure rate is increasing with time. Stress, fatigue, corrosion etc. deteriorate the system, which increases the probability that a failure takes place during this period of time. The shape of the failure rate as represented during the three phases of lifetime, known as "bathtub curve" given in Figures 1(a)-(c). Databases typically provide only the failure rate of useful life, assumed constant. Other distributions such as Gamma, Normale, Log-Normale Birnbaum-Saunders, inverse Gaussian and others may also be considered in the model.

To model the early failures, one must consider the specific distribution of failure times.

Unlike the exponential distribution is used for random failures, these distributions must at least two parameters. Despite the fact that the normal distribution and normal log are frequently used to model the effects of aging, the Weibull distribution is probably the most universally used [10]. Using the latter, the early and random failures and also aging effects can be modeled.

Thus, the rate previously defined is used in situations where one has to deal with early failures or the aging effects. This can be illustrated by considering the effect of accumulated operating time $T_{0}$ over the probability that the entity can survive an additional time t. Assuming that it is defined $R\left(t \mid T_{0}\right)$ as the reliability of an entity that has operated during the time $T_{0}$, the following equation can be written as:

$$
R\left(\frac{t}{T_{0}}\right)=\frac{R\left(T_{0}+t\right)}{R\left(T_{0}\right)}
$$

From the equation

$$
R(t)=\exp \left[-\int_{0}^{t} \lambda(t) \mathrm{d} t\right]
$$

We obtain

$$
R\left(\frac{t}{T_{0}}\right)=\exp \left[-\int_{T_{0}}^{t+T_{0}} \lambda(t) \mathrm{d} t\right]
$$

Time $T_{0}$ can be interpreted as the time of the running-in phase before the system is placed in service. The concern is whether this time contributes to the improvement or deterioration of the system. $T_{0}$ do this, Equation (2) was derived with respect to time $T_{0}$.

$$
\frac{\partial R}{\partial T_{0}}\left(\frac{t}{T_{0}}\right)=-\left[\lambda\left(T_{0}\right)-\lambda\left(T_{0}+t\right)\right] R\left(\frac{t}{T_{0}}\right)
$$

So, if $\lambda$ decreases with time [i.e. $\left.\lambda\left(T_{0}\right)>\lambda\left(T_{0}+t\right)\right]$, then the system can be improved. Otherwise, is to be deteriorated. In the running-in phase, the failure rate is decreasing in general.

The lifetime of a rolling bearing can be divided into two main phases which will be studied here:

- The running-in phase: Forming the first few tens of thousands of cycles of the rolling bearing lifetime, during which the contact geometry and/or roughness, and surface residual stresses are stabilizing.

- The life time phase which comes after the running-in phase and can last several million cycles.

The running-in phase is the first stage of the life time of a bearing. However, this phase is very short and extremely important to the future life span of the rolling bearing because it fixes the steady state in terms of the parts in contact, residual geometry and stresses which are 


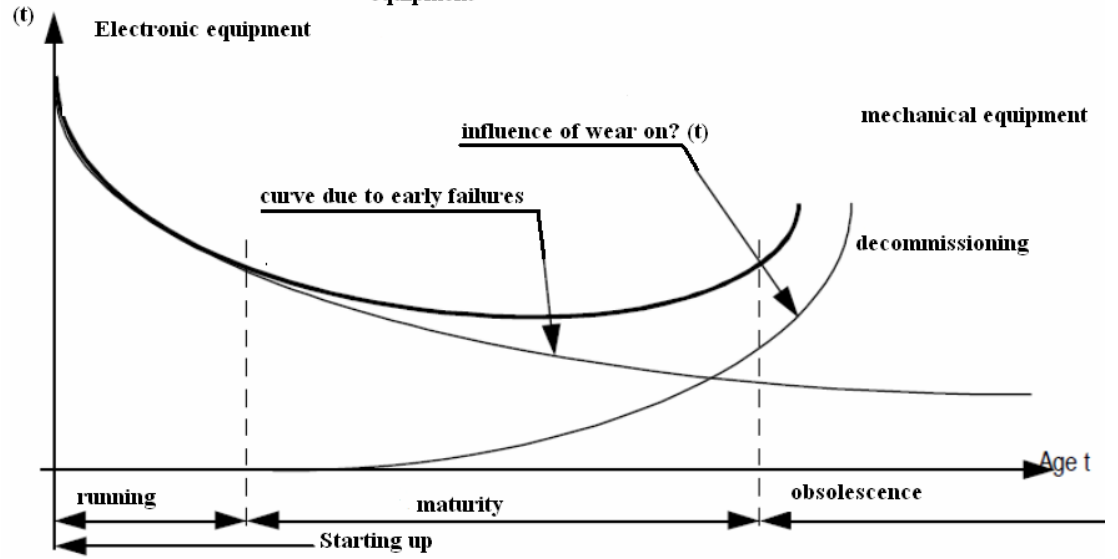

(a)

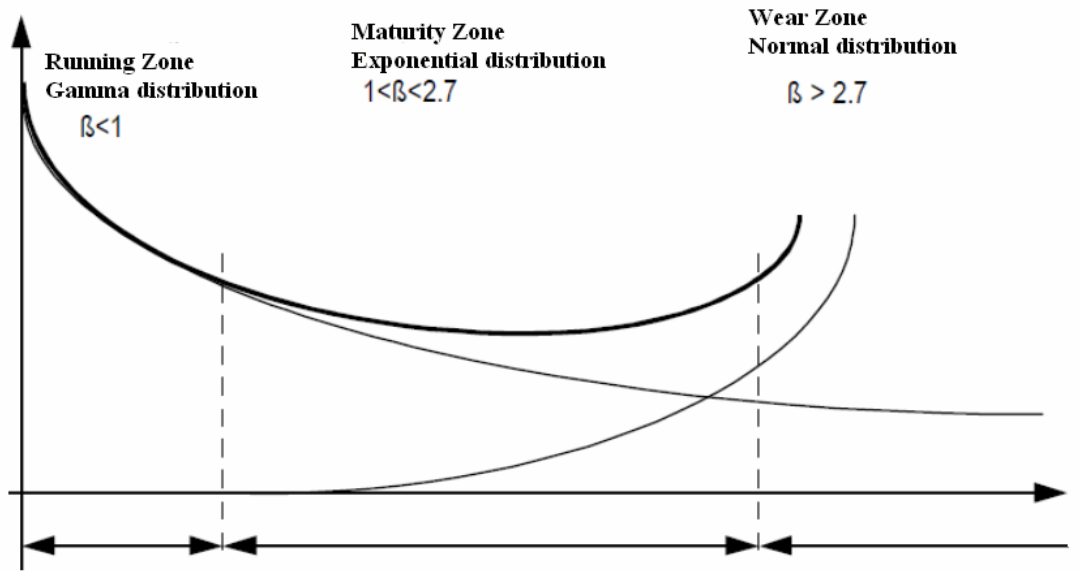

(b)

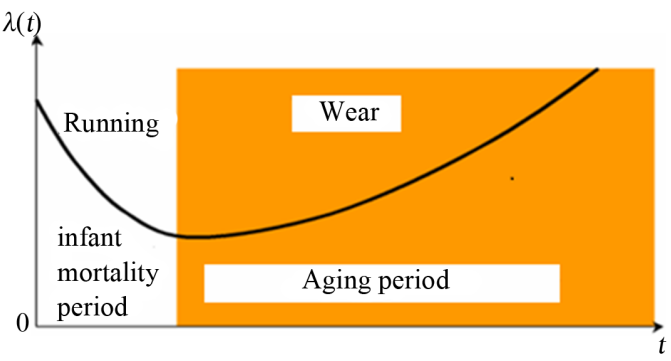

(c)

Figure 1. (a) Failure rate $\lambda_{0}(t)$; (b) Distribution law; (c) Failure rate of a mechanical system.

determining factors in resisting the fatigue [4] of mechanical parts.

The reliability relationship of the running-in phase can be written as follows:

$$
R\left(\frac{t}{T_{0}}\right)=\frac{\exp \left[-\left(\frac{t+T_{0}}{\theta}\right)^{m}\right]}{\exp \left[-\left(\frac{T_{0}}{\theta}\right)^{m}\right]}
$$

By putting $t=T$ and solving for $T$ we obtain:

$$
T=\theta\left\{\ln \left[\frac{1}{R(t)}\right]+\left(\frac{T_{0}}{\theta}\right)^{m}\right\}^{1 / m}-T_{0}
$$

By modeling the running-in phase according to the expression (7), we evaluate the importance of this phase on the additional useful life to the studied system. The results presented below clearly confirm the benefits of the running-in phase. Furthermore, a large enough time 
scale and decreasing from 180 to 4 years has been considered in order to scan a larger number of systems operating within these limits based on a predicted reliability and a shape parameter $\beta$ ranging from 0.5 to 3 , that is to say running-in phase to the aging phase.

\section{Results and Discussion}

Figures 2(a)-(f) show the evolution of additional time to the useful life of the system. Two periods are compared, the running-in phase with a $\beta$ value of 0.5 (running-in phase) and 0.9 (beginning of the useful phase for a scale parameter $\theta$ varying from 180 to 5 years with a reliability

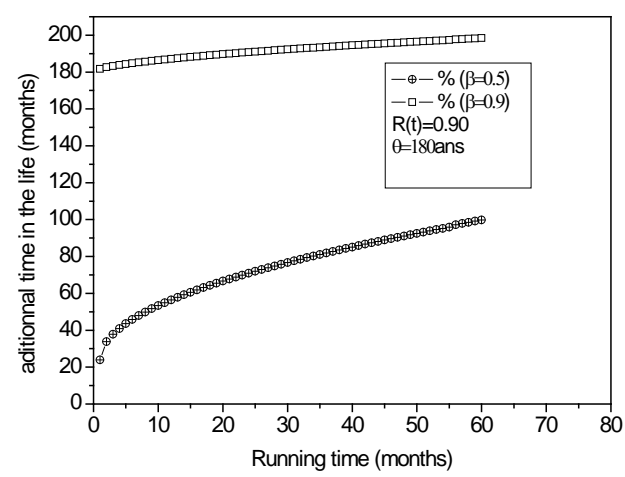

(a)

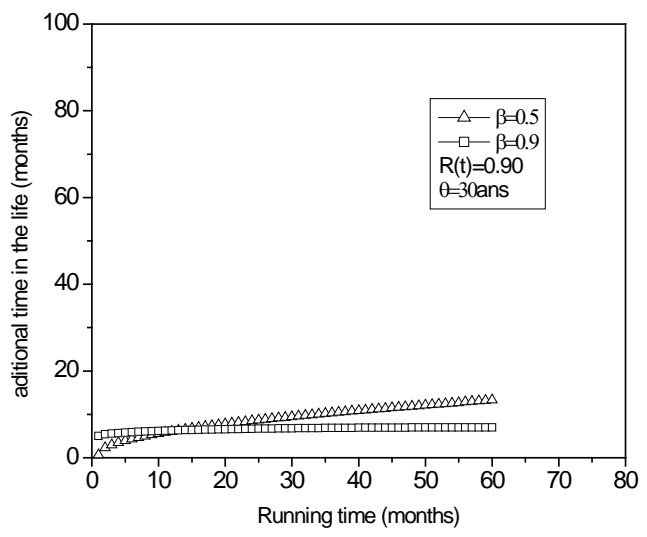

(c)

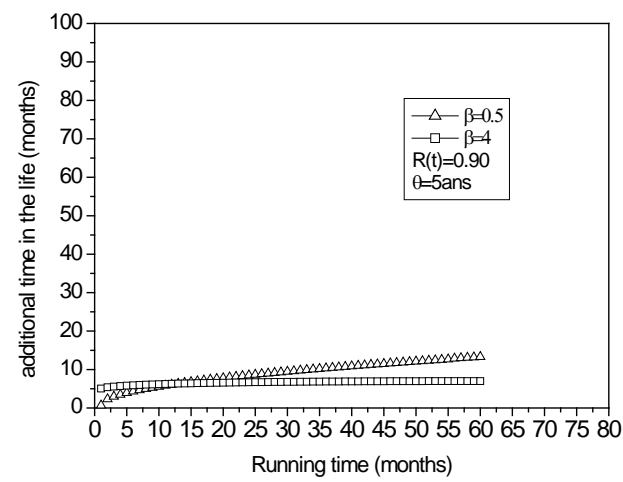

(e) of 0.90 . It can be noticed that for running-in phase when the time $T_{0}=0$ lifetime is approximately 24 months. The addition of one month running-in gives an extra time to the duration of life of 12 months (Figure 2(a)).

Figures 3(a)-(c) express the time variation added to the useful life depending on the essential parameter $\beta$. It can be noticed, for a value of $\beta=0.5$, the opposite effect of added time to the useful life is much more pronounced for values of $\beta=3$. Figure 3(c) shows that as the lifetime becomes shorter, with a shape parameter $\beta>$ 3 (phase of wear), it can be seen that the opposite effect is in good agreement with the logical behavior of repairable systems.

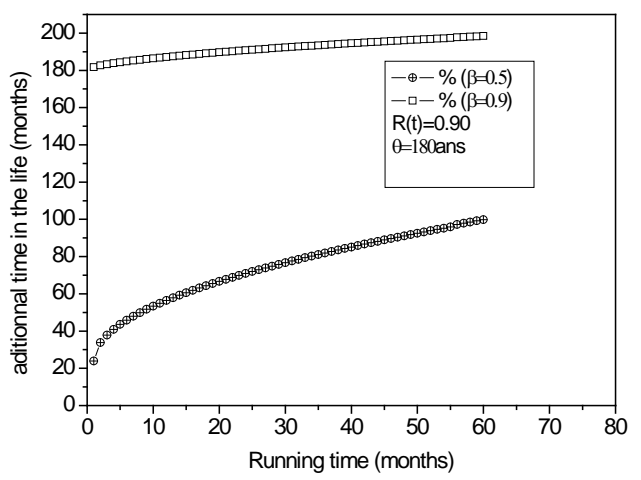

(b)

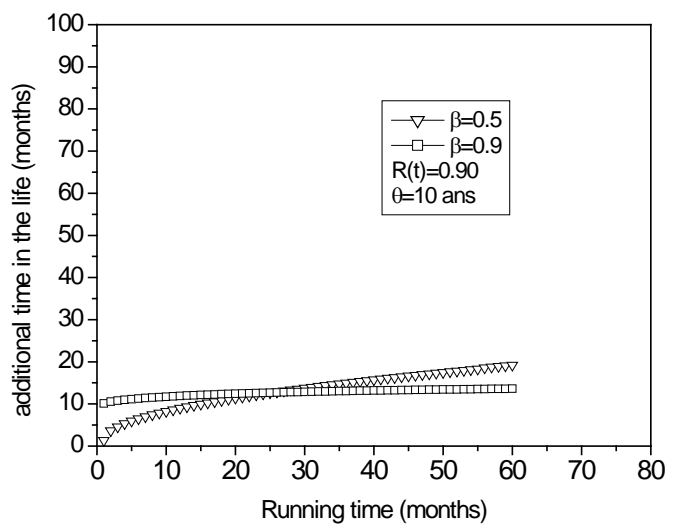

(d)

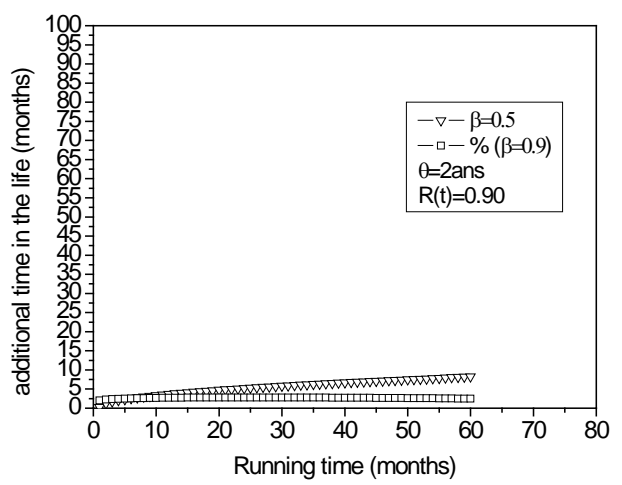

(f)

Figure 2. (a) $\theta=180$ years; (b) $\theta=50$ years; (c) $\theta=30$ years; (d) $\theta=10$ years; (e) $\theta=5$ years; (f) $\theta=2$ years. 


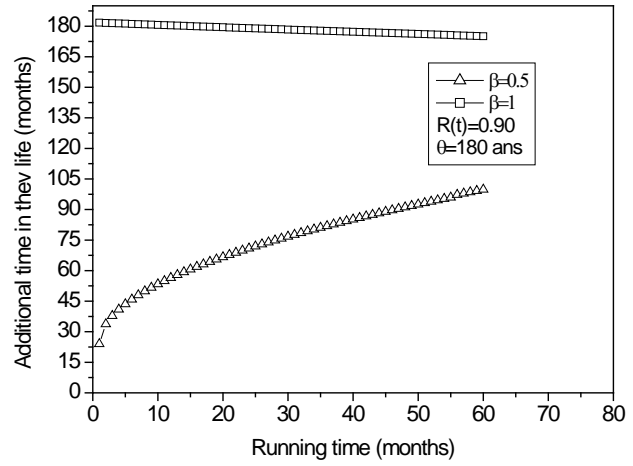

(a)

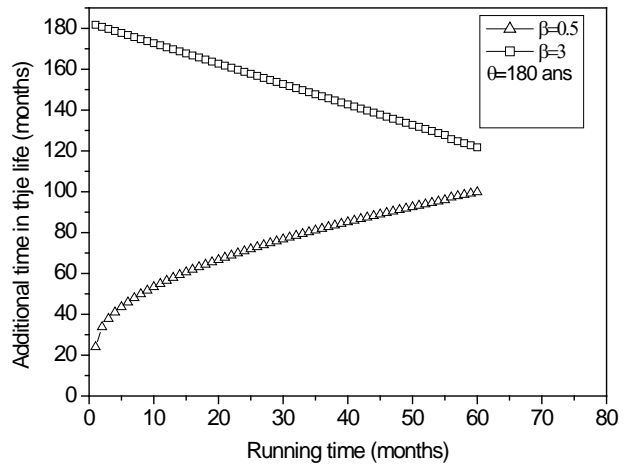

(b)

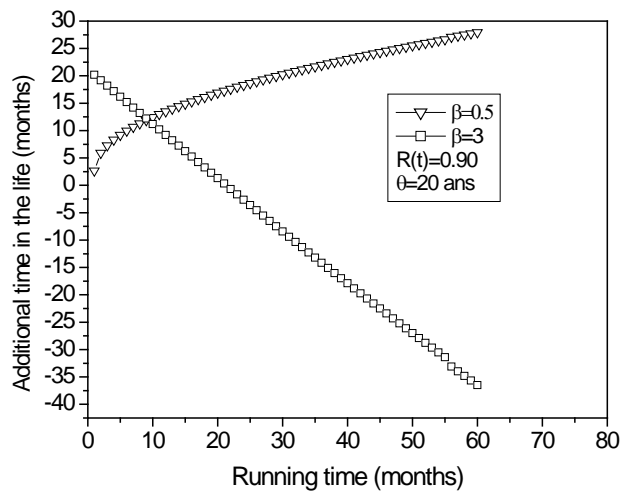

(c)

Figure 3. (a) $\beta=1, \theta=180$ years; (b) $\beta=3, \theta=180$ years; (c) $\beta=3, \theta=20$ years.

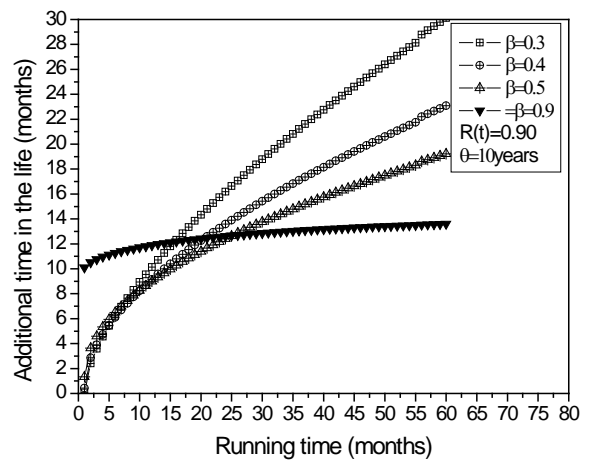

(a)

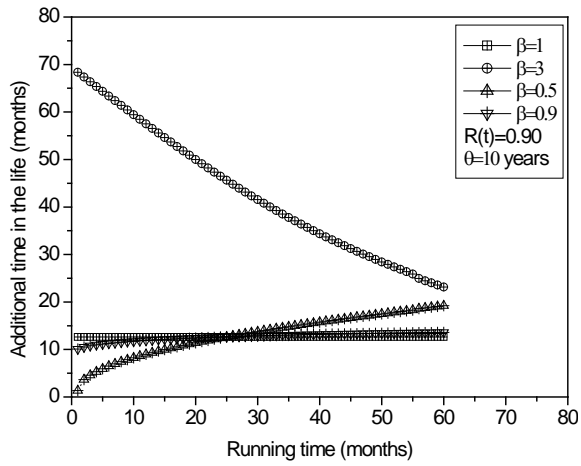

(b)

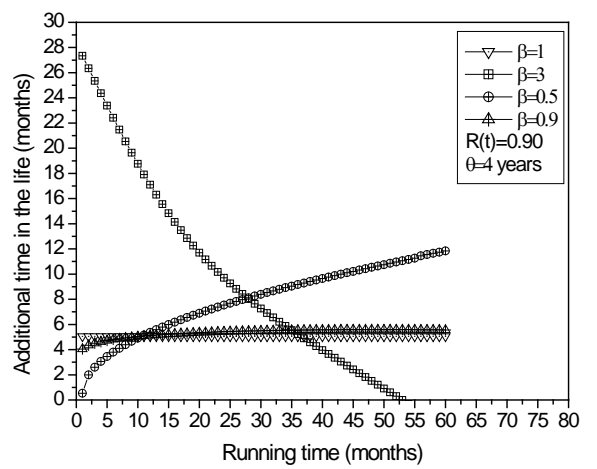

(c)

Figure 4. (a) $\beta=(0.3,0.4,0.5$ and 0.9$) \theta=10$ years; (b) $\beta=(1,3,0.5$ and 0.9$) \theta=10$ years; (c) $\beta=(1,3,0.5$, and 0.9$) \theta=4$ years. 
Figures 4(a)-(c) compare the evolution of additional time to lifespan depending on the parameter $\beta$. It can therefore be noticed, that the additional time to the future lifespan (useful) are more important with the decrease of coefficient $\beta$ which is completely logical. When the scale parameter decreases (Figure 4(c)), it can be noticed that the running-in phase is very narrow.

\section{Conclusion}

The improved behavior of mechanical systems in contact and especially bearings that are almost omnipresent in the majority of rotating mechanical systems is conditioned by the conditions of commissioning. If the running-in phase is properly applied, this will lead to an appreciated operating lifetime. For bearings, whose lifespan is very short compared to that of the entity in which are mounted, this phase is highly recommended because it creates mechanical stability between the parts in contact with surfaces generally have asperities (roughness) which disappear during running-in. This period also provides a high wear resistance to rotating parts and lowers significantly the preventive and systematic maintenance costs.

\section{REFERENCES}

[1] SINTEF Industrial Management, “Offshore Reliability Data (OREDA),” 4th Edition, 2002.

[2] H. Procaccia, P. Aufort and S. Arsenis, "The European Industry Reliability Data Bank (EIReDA),” 3rd Edition,
1998.

[3] L. L. C. Exida, "Electrical \& Mechanical Component Reliability Handbook,” 2005.

[4] G. Thoquenne, "Prévisions des Durées de vie en Fatigue des Roulements," Ph.D. Thesis, Ecole Polytechnique, 2004.

[5] M. Rausand and A. Høyland, "System Reliability Theory, Models, Statistical Methods, and applications,” 2nd Edition, Editions Wiley, New Jersey, 2004.

[6] J. H. Horng, M.-L. Len and J.-S. Lee, “The Contact Characteristics of Rough Surfaces in Line Contact during Running-in Process,” Wear, Vol. 253, 2002, pp. 899-913.

[7] D. H. Kelly, C. G. Barnes, R. W. Freeman and G. W. Critchlow, "Running in and the Enchancement oh Scuffing Resistance,” Proceedings of IME, Vol. 206, pp. 425-429.

[8] C. C. Chou and J. F. Lin, "Tribological Effects of Roughness and Running-in on the Oil Lubricated Line Contacts," Proceedings of IME, Vol. 211, 2002, pp. 209-222.

[9] P. Pawlus, "A Study on the Fonctionnal Properties of Honed Cylinders Surface during Running-in,” Wear, Vol. 176, No. 2, 1994, pp. 247-254. http://dx.doi.org/10.1016/0043-1648(94)90153-8

[10] K. J. Carroll, "On the Use and Utility of the Weibull Model in the Analysis of Survival Data," Controlled Clinical Trials, Vol. 24, No. 6, 2003, pp. 682-701. http://dx.doi.org/10.1016/S0197-2456(03)00072-2 